\title{
APMFT: Anamoly Prediction Model for Financial Transactions Using Learning Methods in Machine Learning and Deep Learning
}

\author{
R. Priyadarshini ${ }^{\mathrm{a}, 1}$, K.Anuratha ${ }^{\mathrm{b}}$, N.Rajendran ${ }^{\mathrm{c}}$ and S. Sujeetha ${ }^{\mathrm{d}}$ \\ ${ }^{\mathrm{a}, \mathrm{c}}$ Assistant Professor, Dept of IT, B.S. AbdurRahman Crescent Institute of Science and \\ Technology, Chennai \\ ${ }^{b, d}$ Assistant Professor, Dept of IT, Sri Sai Ram Institute of Technology, Chennai
}

\begin{abstract}
Anamoly is an uncommon and it represents an outlier i.e, a nonconforming case.According to Oxford Dictionary of Mathematics anamoly is defined as an unusal and erroneous observation that usually doesn't follow the general pattern of drawn population. The process of detecting the anmolies is a process of data mining and it aims at finding the data points or patterns that do not adapt with the actual complete pattern of the data.The study on anamoly behavior and its impact has been done on areas such as Network Security, Finance, Healthcare and Earth Sciences etc.,.The proper detection and prediction of anamolies are of great importance as these rare observations may carry siginificantinformation.Intoday'sfinanicial world, the enterprise data is digitized and stored in the cloudand so there is a significant need to detect the anaomalies in financial data which will help the enterprises to deal with the huge amount of auditing The corporate and enterprise is conducting auidts on large number of ledgers and journal entries. The monitoring of thosekinds of auidtsis performed manually most of the times. There should be proper anamoly detection in the high dimensional data published in the ledger format for auditing purpose.This work aims at analyzing and predicting unusal fraudulent financial transations by emplyoing few Machine Learning and Deep Learning Methods. Even if any of the anamoly like manipulation or tampering of data detected, such anamolies and errors can be identified and marked with proper proof with the help of the machine learning based algorithms. The accuracy of the prediction is increased by $7 \%$ by implementing the proposed prediction models.
\end{abstract}

Keywords:Anamoly detection, Deep Learning, Machine Learning, financial data, nueural network model, CNN.

\footnotetext{
${ }^{1}$ PriyadharshiniR, ${ }^{b}$ Assistant Professor, Dept of IT, B.S. AbdurRahman Crescent Institute of Science and Technology, Chennai;

E-mail: rspdarshini@gmail.com
} 


\section{Introduction}

Detecting anomalies is essential in finance sector as this may reveal illegitimate activities such as fraudulent risk, theft of identity, network intrusion which may lead to unsoughtconsequences such as service disruptions and other failures. As the dimension of data is increasing in large scale as there is change in finance environments, growth in digital platforms, it becomes very challenging to detect the unusual activities. Many ideas involving semi-supervised learning, deep learning algorithm and graph based methods to address this challenge in anmoly detection. In sectors like finance, when the data exponentialyincreses then the methods may not work in realtime and may also time consuming. Multiple industries are witnessing an exponential increase in the availability of streaming large volume of data. Anomaly detection techniques are generally aimed at finding the what is considered as normal and how to differentiate the abnormality from normality.

\section{Problem Statement}

Since the introduction of Digital Transactions, the scammers have found methods to expoit public and use the credit cards, debit cards or digital credentials to have unauthorized access.Fraud has been a stumbling block since the years in domains like Finance, Healthcare,Insurance and several other financial domains. Due to the growth in digital transactions through diverse payment options, such as PhonePe, Google pay, Paytm, etc., there is increase in fraudulent activities also. Since no system is always consistent and there is always an ambiguity.In the proposed system we would like to address few fraudulent transactions such as Embezzlement.To identify these kinds of unusual activities and to stop them from happening again,we have developed a model using various Learning Algorithms and Statistical Methods. The model will be learning from the training data and used for prediction using the previous knowledge and stored patterns.

\section{Literature Survey}

\begin{tabular}{|c|c|c|}
\hline Title & Proposed Techniques / Model & Observations \\
\hline $\begin{array}{l}\text { Rajan } G \text { et al. , in their } \\
\text { paper Construction of } \\
\text { Optimal Portfolio } \\
\text { Using Sharpe Index } \\
2018[1]\end{array}$ & $\begin{array}{l}\text { Discussed the grouping of securities on } \\
\text { shares, bonds and finance market tools. } \\
\text { The process of integration of the } \\
\text { various assets to get an optimal profit } \\
\text { with less financial threat is termed as } \\
\text { portfolio construction. They have } \\
\text { summarized that the process can be } \\
\text { simplified by using Sharpe model to } \\
\text { associate the profit in a security to a } \\
\text { market index, by adapting CAPM } \\
\text { theory which defines the relationship } \\
\text { of an assest with its systematic } \\
\text { possible threats }\end{array}$ & $\begin{array}{l}\text { The portfolio used } 5 \\
\text { securities and its Investment } \\
\text { is from } 4 \% \text { to } 43.39 \% \\
\text { considering HDFC Bank Ltd. } \\
\text {, HDFC Ltd. } \\
\text { ICICI Bank Ltd, TCS Ltd. } \\
\text { and TATA Motors Ltd with } \\
\text { HDFC Bank Ltd with } \\
\text { maximum weightage and } \\
\text { TCS Ltd ith least weightage. } \\
\text { The proposed method may } \\
\text { not suitable for consistent } \\
\text { prediction of security threats } \\
\text { financial data as stock maket } \\
\text { is non-volatile }\end{array}$ \\
\hline
\end{tabular}


"The Single Index Considered ten financial companies Model \& The from National Stock Exchange and the Construction Of Bank Price Index was accounted Optimal Portfolio: A during 2009 and 2013.

Case Of Banks Listed

On Nse India” [2]
Proposed the available options for the investors analysing the returns, risk on investment. Wecant accurately analyse and predict as the financial market is not static

\section{Proposed Model}

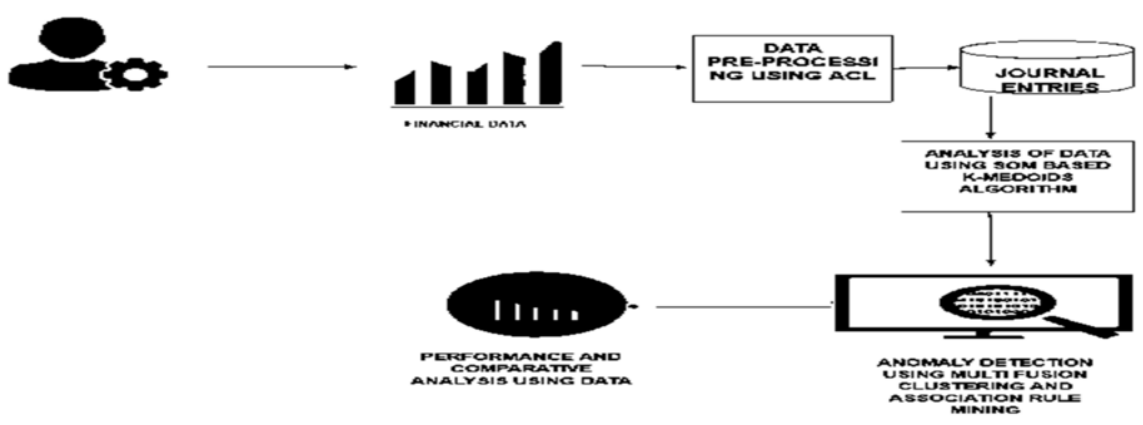

Figure 1.System Architecture

\subsection{Modules}

\subsubsection{Module 1}

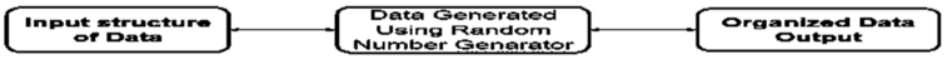

Figure 2. Data Generation and Data Collection

\subsubsection{Module 2}

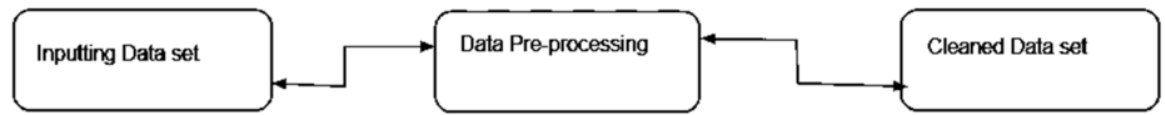

Figure 3.Data Preprocessing 


\subsubsection{Module 3}

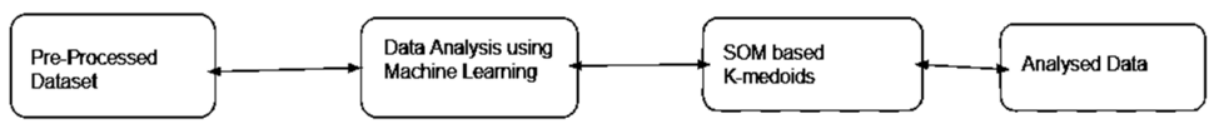

Figure 4.Data Analysis

\subsubsection{Module 4}

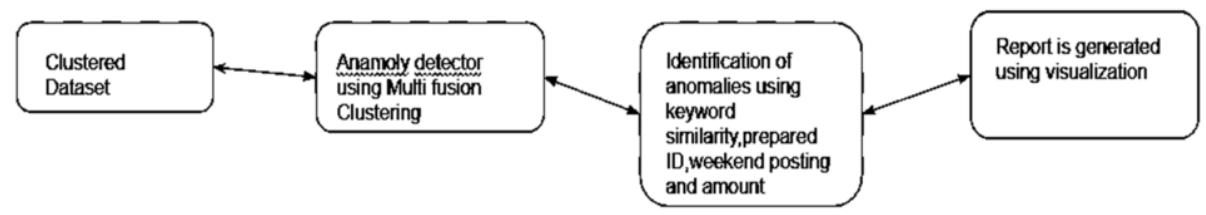

Figure 5. Anamoly Detection In Analysed Data Using Multi Fusion Clustering

\section{Results And Discussions}

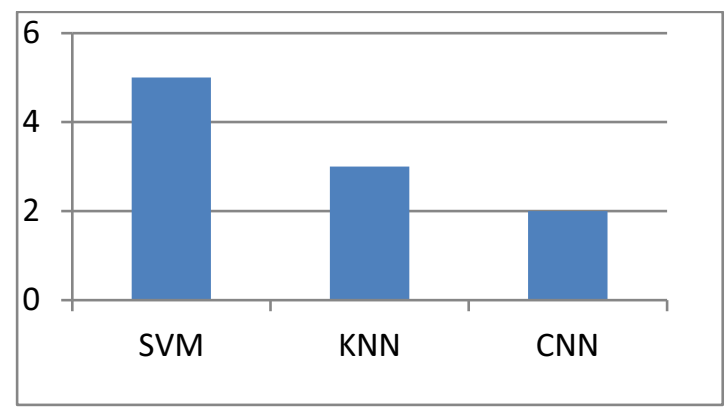

Figure 6. Frequency on right prediction

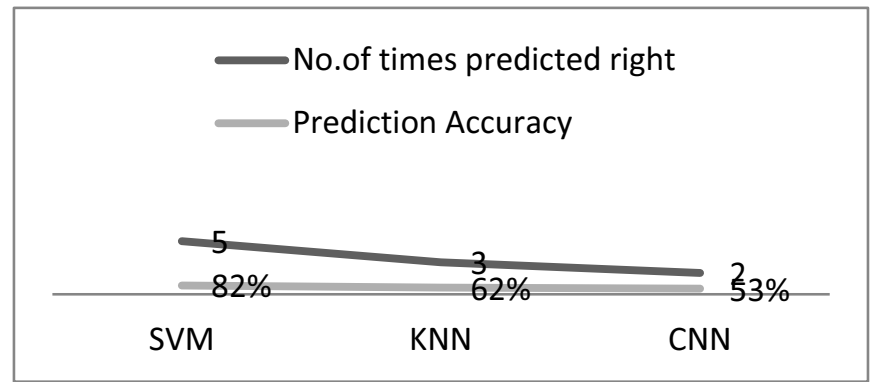

Figure 7. SVM outperforms KNN and CNN 


\section{Conclusion}

This paper provided insights on Machine Learning and Deep Learning methods to detect the fradulent transactions and attempted to find the best method for better prediction. The study identified that for high dimensional data SVM classifier is best suited to predict the unusual financial transactions. We have tried only with the supervised learning methods and it would be better if the classifiers are built using unsupervised learning methods as the financial data are inconsistent and volatile in nature.

\section{References}

[1] Chakraborty, Subhodeep\& Patel, Ajay. (2018), Construction of Optimal Portfolio Using Sharpe's Single Index Model and Markowitz Model An Empirical Study on Nifty, 50 Stock. 5. 86-103.

[2] Singh, Saurabh\&Gautam, Jayant. (2014), The single index model \& the construction of optimal portfolio: A case of banks listed on NSE India, Risk Governance and Control: Financial Markets \& Institutions. 4. 10.22495/rgcv4i2c1art3.

[3] Marisetty, Nagendra. (2012), Construction of Optimal Portfolio using Sharpe Index Model, SSRN Electronic Journal. 10.2139/ssrn.3456697.

[4] Ambeth Kumar.V.D et,al, Enhancement in Footprint Image using Diverse Filtering Technique. Procedia Engineering journal, Volume 8, No.12, 1072-1080, 2012 . [doi:10.1016/j.proeng.2012.01.965]

[5] Ambeth Kumar.V.D et.al., .Performance Improvement Using an Automation System for Segmentation of Multiple Parametric Features Based on Human Footprint. for the Journal of Electrical Engineering \& Technology , vol. 10, no. 4, pp.1815-1821 , 2015. [http://dx.doi.org/10.5370/JEET.2015.10.4.1815]

[6] Ambeth Kumar.V.D et.al. A Survey on Face Recognition in Video Surveillance.Lecturer Notes on Computational and Mechanism, Vol. 30, pp: 699-708, 2019

[7] Ambeth Kumar.V.D .Precautionary measures for accidents due to mobile phone using IOT. Clinical eHealth, Volume 1, Issue 1, March 2018, Pages 30-35.

[8] K. Sabarinathan et.al ., " Machine Maintenance Using Augmented Reality”, 3rd International Conference on Communication and Electronics Systems (ICCES), 2018. (DOI: 10.1109/CESYS.2018.8723900)

[9] R. Subha Shini et.al., " Recurrent Neural Network based Text Summarization Techniques by Word Sequence Generation",IEEE International Conference on Inventive Computation Technologies (ICICT), 2021, DOI: 10.1109/ICICT50816.2021.9358764 